\title{
Knowledge regarding prevention of road traffic accidents among the adolescents in a community at Dharan Municipality
}

\author{
Neela Subba ${ }^{1}$ and Dipty Subba ${ }^{2 *}$ \\ ${ }^{I}$ TUIOM, Nursing Campus, Biratnagar, Nepal \\ ${ }^{2}$ PUCMAS, Gothgaun, Morang, Boratnagar, Nepal \\ *E-mail: diptysubba@yahoo.com
}

\begin{abstract}
Descriptive study with the aim to assess knowledge regarding prevention of road traffic accidents was done by administrating self-structured questionnaire among 100 adolescents (between 10-19 years) at Dharan Municipality. Questionnaire includes the information regarding demographic and knowledge about meaning, causes and prevention of road traffic accidents. Among the respondents $55 \%$ were male and $45 \%$ were female. Driver responsibility and not obeying traffic signals for occurrences of RTA, use of safety seat belts for minimizing Road Traffic Accident, were the most responses provided $85 \%, 91 \%$ and $81 \%$ respectively. Overall, only $33.34 \%$ had good knowledge regarding prevention of road traffic accidents. The study concludes the need for knowledge about accident prevention.
\end{abstract}

Key words: Adolescents, road traffic accidents

\section{Introduction}

Road traffic accidents (RTA) are considered as one of the important public health problems around the world and are the $9^{\text {th }}$ leading cause of death by the year 2020 (Murray and Lopez, 1996). Global status report on road safety shows that over 1.2 million people die each year on the roads worldwide and between 20 to 50 million suffer non-fatal injuries. Among the children between the age of 5 and 14 years' road traffic injuries alone ranked as the number one cause of disease burden, and as the number three cause among those in the age group 15 to 29 years with a male female ratio of 3: 1 (Krug, 1999).

It is well documented that RTA issue has been a global concern and viewed as a prioritized research area. In Nepal, this area has been almost negligible and out of public attention. Most of the road accident is due to increased vehicle fleet and speed. The number of death of passengers and pedestrians per 10000 vehicles is also increasing steeply since 2006 (Poudel-Tandukar et al., 2007). The trend of minor injury, serious injury and fatality are also in increasing trend and is steeply rising from 2006 to 2010 (Thapa, 2013).

\section{Materials and Methods}

A community based descriptive study was conducted in Janapath, Dharan Municipality of eastern region of Nepal among 100 adolescents which was calculated by using 4pq/12 in 95\% CI where allowable error was taken as $10 \%$ and prevalence $50 \%$. The calculated samples were selected by purposive sampling technique. Data was collected by using self-administered questionnaire which included 10 each questions on a demographic and knowledge about road traffic accidents. 


\section{Results and Discussion}

Out of 100 respondents, the mean age of respondents was 15.1 years and majority $(55 \%)$ of them was male. Most (85\%) of the adolescents were the permanent residents of Dharan. $50 \%$ were studying in secondary level, 69\% belongs to nuclear family (fig. 1).

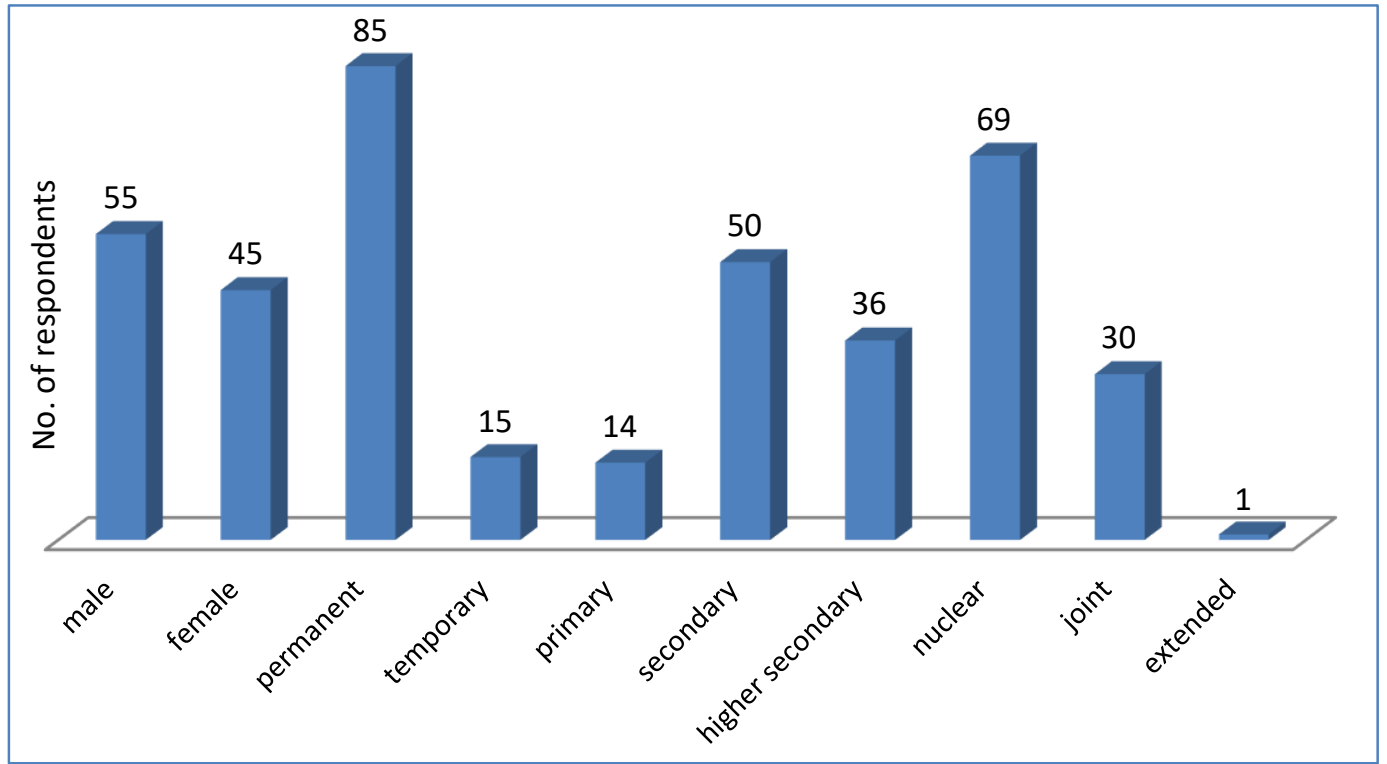

Figure 1. Demographic variables of the respondents

The present study examined the causes and prevention of RTA, where most $(33.34 \%)$ of the respondents had poor knowledge which is supported by the WHO report. It is evident that there is a need for education and awareness regarding RTA. Adolescents show different risky behaviors around the road. Such behaviors might not only put themselves at risk but also lead to pedestrian injury. Adolescents spend no more time waiting on the curb before crossing than do young children (Velde et al., 2005). They are often seen running across the road instead of walking and do not check for oncoming traffic (Zeedyk et al., 2002) and forcing traffic to change its trajectory (Khan et al., 1999). Moreover, Joly et al., (1991) reported that one third of adolescents who were injured crossing the street had disobeyed pedestrian traffic rules. Another study found that most injured adolescents routinely use the streets and sidewalks as play areas (Posner et al., 2002)

When the knowledge was compared in terms of gender, more $(41.82 \%)$ male respondents have good knowledge than females (Tab. 1). But no significant differences was found in knowledge level in terms of gender $(\mathrm{p}>0.05)$ but different from the results of some other studies done in Turkish students (Jonah, 1986) which shows female had more knowledge than males.

This study examined the effect of age on knowledge which showed no any significant relation. While some studies in literature showed with the increase in age, knowledge about prevention of RTA increases as well (Ulleberg, 2008). This variation may be due to the small number of sample size. 
Table 1 Distribution of knowledge about road traffic accidents $(\mathrm{N}=100)$

\begin{tabular}{lll}
\hline SN & Response & F \\
\hline 1 & Knowledge by traffic rules & 94 \\
& Follow the traffic signals & 91 \\
& Use zebra crossing, footpath, watch left and right before crossing the road & 27 \\
Walk and drive/ride on the right direction & 14 \\
Drive/riden vehicle with the driving license & 37 \\
Use helmet, seat belt, & 6 \\
Use indicator, headlight and horn whenever necessary & 9 \\
Do not overload vehicle & \\
\hline 2 & Knowledge by prevention of RTA & 94 \\
Controls speed & 94 \\
Follows traffic signal & 11 \\
Check condition of the vehicle going out & 80 \\
Use zebra crossing, footpath, watch left and right before crossing the road & 7 \\
Do not take body parts (head and hand) out of the vehicle while driving & 28 \\
Does not talk on mobile phone while driving & 75 \\
\hline Knowledge by minimizing RTA & 75 \\
Enforcing speed limits & 46 \\
Increase traffic personnel on the road & 81 \\
Speed bumps & 19 \\
Safety seat belts & \\
Drivers not obeying traffic signals & 86 \\
\hline Knowledge about dangerous factors for causing RTA & 91 \\
Inexperienced driver & 82 \\
Not obeying traffic signals & 78 \\
Raising speed limit & 64 \\
Narrow and broken roads & 89 \\
Poor street lights & 11 \\
Overloaded vehicle and high speed & 8 \\
Others & 1 \\
Drinking and driving & \\
Use of mobile phones while driving & \\
Crossing the road haphazardly & \\
\hline & & \\
& & \\
& & \\
&
\end{tabular}

There is no significant differences found in the knowledge of respondents in terms of educational level $(<0.05)$. It was seen that majority of respondents $(57.14 \%)$ from primary level had good knowledge regarding RTA, but showed no any significant association. This finding is opposed to the other study where $63.8 \%$ secondary level students had good knowledge (Olsson et.al, 2003).

The association of RTA test scores across the different independent variables was determined and concluded that none of the independent variables (age, gender, education and inhabitant) have significant association with the test scores of adolescents' knowledge regarding prevention of RTA (P>0.05). 12\% of the respondents have encountered with the incident about the RTA. The study concluded that the significant numbers of adolescents have a very poor knowledge about prevention on road traffic accidents. 


\section{References}

Joly, M.F., P.M. Foggin \& I.B. Pless .1991. Geographical and socio-ecological variations of traffic accidents among children. Soc Sci Med 33(7): 765-9. PMID: 1948168

Jonah, B.A.1986. Accident risk and risk-taking behavior among young drivers. Accident analysis and prevention 18(4): 255-271. doi:10.1016/0001-4575(86)90041-2

Khan, F.M., M. Jawaid, H. Chotani \& S. Luby 1999. Pedestrian environment and behavior in Karachi, Pakistan. Accid Anal Prev 31(4): 335-9. doi:10.1016/S0001-4575(98)00075-X

Krug, E. 1999. Injury: a leading cause of the global burden of disease. Geneva: WHO. (Accessed: 11 Dec 2011).

Murray C \& A. Lopez .1996. The Global Brden of Disease. Vol. 1. Cambridge, MA: Harvard University Press; 1996.

Olsson, C.A., L. Bond, J.M. Burns, D.A. Vella \& S.M. Sawyer 2003. Adolescent resilience: a concept analysis, Journal of Adolescence 26(10): 1-11. doi:10.1016/0001-4575(86)90041-2

Posner, J., E. Liao, F. Winston, A. Cnaan, K. Shaw \& D. Durbin 2002. Exposure to traffic among urban children injured as pedestrians. Inj Prev 8(3): 231-235. doi:10.1136/ip.8.3.231

Poudel-Tandukar, K., S. Nakahara, M. Ichikawa, K.C. Poudel \& M. Jimba 2007. Risk perception, road behavior, and pedestrian injury among adolescent students in Kathmandu, Nepal. Inj Prev. 13(4): 258-263. doi:10.1136/ip.2006.014662

Thapa, A.J. 2013. Status paper on road safety in Nepal. DDG, Department of Road. (www.dor.gov.np/documents/Status_Paper\%20_2013.pdf)

Ulleberg, P. 2001. Personality subtypes of young drivers. Transportation Research Part F: Traffic Psychology and Behavior 4(4): 279-297. doi: 10.1016/s1369-8478(01)00029-8

Velde, A.F., J. Van der Kamp, J.A. Barela \& G.J. Savelsbergh 2005. Visual timing and adaptive behavior in a road-crossing simulation study. Accid Anal Prev 37(3): 399-406. doi:10.1016/j.aap.2004.12.002

Zeedyk, M.S., L. Wallace \& L. Spry. 2002. Stop, look, listen, and think? What young children really do when crossing the road. Accid Anal Prev 34 (1):43-50. PMID: 11789574 